\title{
Short-term heat load forecasting for single family houses
}

\author{
Bacher, Peder; Madsen, Henrik; Nielsen, Henrik Aalborg; Perers, Bengt
}

Published in:

Energy and Buildings

Link to article, DOI:

10.1016/j.enbuild.2013.04.022

Publication date:

2013

Document Version

Peer reviewed version

Link back to DTU Orbit

Citation (APA):

Bacher, P., Madsen, H., Nielsen, H. A., \& Perers, B. (2013). Short-term heat load forecasting for single family houses. Energy and Buildings, 65, 101-112. https://doi.org/10.1016/j.enbuild.2013.04.022

\section{General rights}

Copyright and moral rights for the publications made accessible in the public portal are retained by the authors and/or other copyright owners and it is a condition of accessing publications that users recognise and abide by the legal requirements associated with these rights.

- Users may download and print one copy of any publication from the public portal for the purpose of private study or research.

- You may not further distribute the material or use it for any profit-making activity or commercial gain

- You may freely distribute the URL identifying the publication in the public portal

If you believe that this document breaches copyright please contact us providing details, and we will remove access to the work immediately and investigate your claim 


\title{
Short-term heat load forecasting for single family houses
}

\author{
Peder Bacher, Henrik Madsen \\ DTU Compute, Technical University of Denmark, DK-2800 Lyngby, Denmark \\ Henrik Aalborg Nielsen
}

ENFOR A/S, DK-2970 Hørsholm, Denmark

Bengt Perers

DTU Civil Engineering, Technical University of Denmark, DK-2800, Lyngby, Denmark

\begin{abstract}
This paper presents a method for forecasting the load for space heating in a single-family house. The forecasting model is built using data from sixteen houses located in Sønderborg, Denmark, combined with local climate measurements and weather forecasts. Every hour the hourly heat load for each house the following two days is forecasted. The forecast models are adaptive linear time-series models and the climate inputs used are: ambient temperature, global radiation and wind speed. A computationally efficient recursive least squares scheme is used. The models are optimized to fit the individual characteristics for each house, such as the level of adaptivity and the thermal dynamical response of the building, which is modeled with simple transfer functions. Identification of a model, which is suitable for all the houses, is carried out. The results show that the one-step ahead errors are close to white noise and that practically all correlation to the climate variables are removed. Furthermore, the results show that the forecasting errors mainly are related to: unpredictable high frequency variations in the heat load signal (predominant only for some houses), shifts in resident behavior patterns and uncertainty of the weather forecasts for longer horizons, especially for solar radiation.
\end{abstract}

Keywords: Heat load, single-family house, building heat dynamics, forecasting, numerical weather predictions, thermal, cooling

\section{Introduction}

The transition to an energy system based on renewables requires methods for forecasting of power load and generation. In Denmark around $40 \%$ of the total energy consumption is related to buildings and around $29 \%$ of the energy used for space heating is covered by individual oil or gas fired furnaces [1], which is neither economically feasible nor environmentally friendly technologies. The Danish Commission on Climate Change Policy recommends replacement with alternative technologies, especially with electric heat pumps since this is one of the socio-economically cheapest

Email address: pbac@dtu.dk (Peder Bacher)

$U R L$ : henrikmadsen.org (Henrik Madsen), www.enfor.eu (Henrik Aalborg Nielsen) 
alternatives in the transition to an energy system without fossil fuels in Denmark. Hence, new and alternative technologies for building space heating based on renewable energy production are of high interest, both for individual and district heating. Especially electrical heating systems since large amounts of wind power are available, which creates a need for flexible load in order to absorb the increasingly volatile production. As the level of electrical load increase, load-shifting in shorter periods of time for peak-shaving of the diurnal electrical consumption is a valuable service to the grid [2]. Flexible load can be achieved with thermal energy buffering, both in individual heating and district heating, where huge thermal storage capacity is available. Several studies consider the possibilities for flexible heating, for example [3] and [4] who present methods for energy storage in the thermal mass of buildings, and [5] and [6] who consider load-shifting for cooling of buildings. The present paper presents a method for forecasting of the power load for space heating in a single-family house, referred to as the space heat load or simply heat load. The heat load forecasts can be used as input to model predictive control, which can be used for optimized load-shifting, for example for operation under energy markets where relocation of load to periods with cheap energy is rewarded. The method can just as well be used for forecasting of cooling load and used for load-shifting with cool thermal storage. [7] presents solar a combisystem, which is a heating system based on a solar thermal collector and electrical heating, where a hot water tank is used for thermal energy storage. Forecasting of the heat load is vital for optimal and effective use of the thermal storage in such a system.

Forecasting of the heat load is carried out for sixteen houses located in Sønderborg, Denmark. Every hour a new forecast is calculated of the hourly heat load up to 42 hours ahead. The houses are generally built in the sixties and seventies, with a floor plan in the range of 85 to $170 \mathrm{~m}^{2}$ and constructed in bricks. Climate observations - which are measured at the local district heating plant within 10 kilometers from the houses - together with numerical weather predictions (NWPs) are used as input to the forecasting model. The NWPs are from the HIRLAM-S05 [15] model and provided by the Danish Meteorological Institute. For each house only the total heat load, including both space heating and hot water heating in a single signal, is available. The total heat load signal is separated into two signals: one for space heating and one for hot water heating, and then the space heating is forecasted. The splitting allows for a clear view of the effects stemming from heat loss to the ambient and heat gains from solar radiation etc., since the noisy peaks from hot water heating are filtered out. The indoor temperature is not available, but this is accounted for in the models by including a diurnal curve to model nightly setback and behavioral patterns of the residents e.g. heat from electrical appliances used for cooking.

Many approaches to load forecasting are found in the literature. A good overview of references are given by [8], who also built load forecasting models using dynamic factor models. [9] use a model based on the ambient temperature and a weekly pattern for forecasting of the heat load in district heating, i.e. the total heat load for many houses. 10 use a grey-box model based on transfer functions for building thermal load prediction and validates it on a 50 floors multi-purpose building. The models applied in the present study are originally developed and used for forecasting of heat load in district heating, as described in [11] and [12]. The heat load summed for many houses have less high frequency variation, due to the averaging effects, compared to the heat load for a single house. Emphasis in the present study is put on the variability in heat load among the individual houses, for example some react more than others to solar radiation and especially the diurnal pattern is very different among the studied houses.

The paper starts with a section in which the data and the NWPs are described. This is 
followed by a presentation of the modeling approach and the model identification, where a suitable forecasting model is found together with a dynamic model for the remaining noise. Finally, the results are presented, and the method is discussed and concluded.

\section{Data}

The data used in the study consists of measurements from sixteen houses located in Sønderborg, Denmark, local climate measurements and NWPs. All times are in UTC and the time stamp for average values are set to the end of the time interval.

\subsection{Heat load measurements}

The houses are typical Danish single family houses from the sixties and seventies. Only houses with radiator heating are considered. A single signal for each house is used. It consists of the total energy for both space heating and hot water heating. The measurements consist of 10 minutes average values. Time series plots of the entire period, spanning nearly two and a half years, for four of the houses are shown in Figure 1. Also shown, with red lines, is the distribution over time as smoothing estimates of the $0 \%, 2 \%, \ldots, 98 \%, 100 \%$ quantiles. They are estimated using local quantile regression [13, where the weighting is local in time. They clearly show that the distribution of the measurements is heavily skewed, as only two percent of the values are between the two upper lines, which cover more than half of the range. The reason for this skewness is seen from Figure 2, where the measurements from a period of 10 days for the same four houses are plotted. The hot water heat load consists of high frequency spikes added to the more slowly varying space heat load. The highest peaks are from showers and cause the high skewness. Since it is wanted to study the space heating part, then each signal is separated into a space heating part and a hot water heating part - with the method described in [14] applied causally. On the figure the part of the signal identified as hot water heat load is marked with red, note that it is added on top of the space heat load in the plot. After the splitting the series are re-sampled into hourly average values. The hourly space heating for a single house is denoted by

$$
\left\{Q_{t} ; t=1, \ldots, N\right\}
$$

where $N=21144$ and the unit is $\mathrm{kW}$. Notice that no distinction in between the houses is used in the notation, but when the results are presented the house number, ranging from 1 to 16, is clearly stated.

\subsection{Local climate observations}

The local climate observations are from a weather station at the district heating plant in Sønderborg, which is less than 10 kilometers from the houses. The observations are re-sampled to hourly average values and the following time series are used:

$$
\begin{aligned}
\text { Ambient temperature: } & \left\{T_{t}^{\mathrm{a}, \mathrm{obs}} ; t=1, \ldots, N\right\} \\
\text { Global radiation: } & \left\{G_{t}^{\mathrm{obs}} ; t=1, \ldots, N\right\} \\
\text { Wind speed: } & \left\{W_{t}^{\mathrm{s}, \mathrm{obs}} ; t=1, \ldots, N\right\}
\end{aligned}
$$




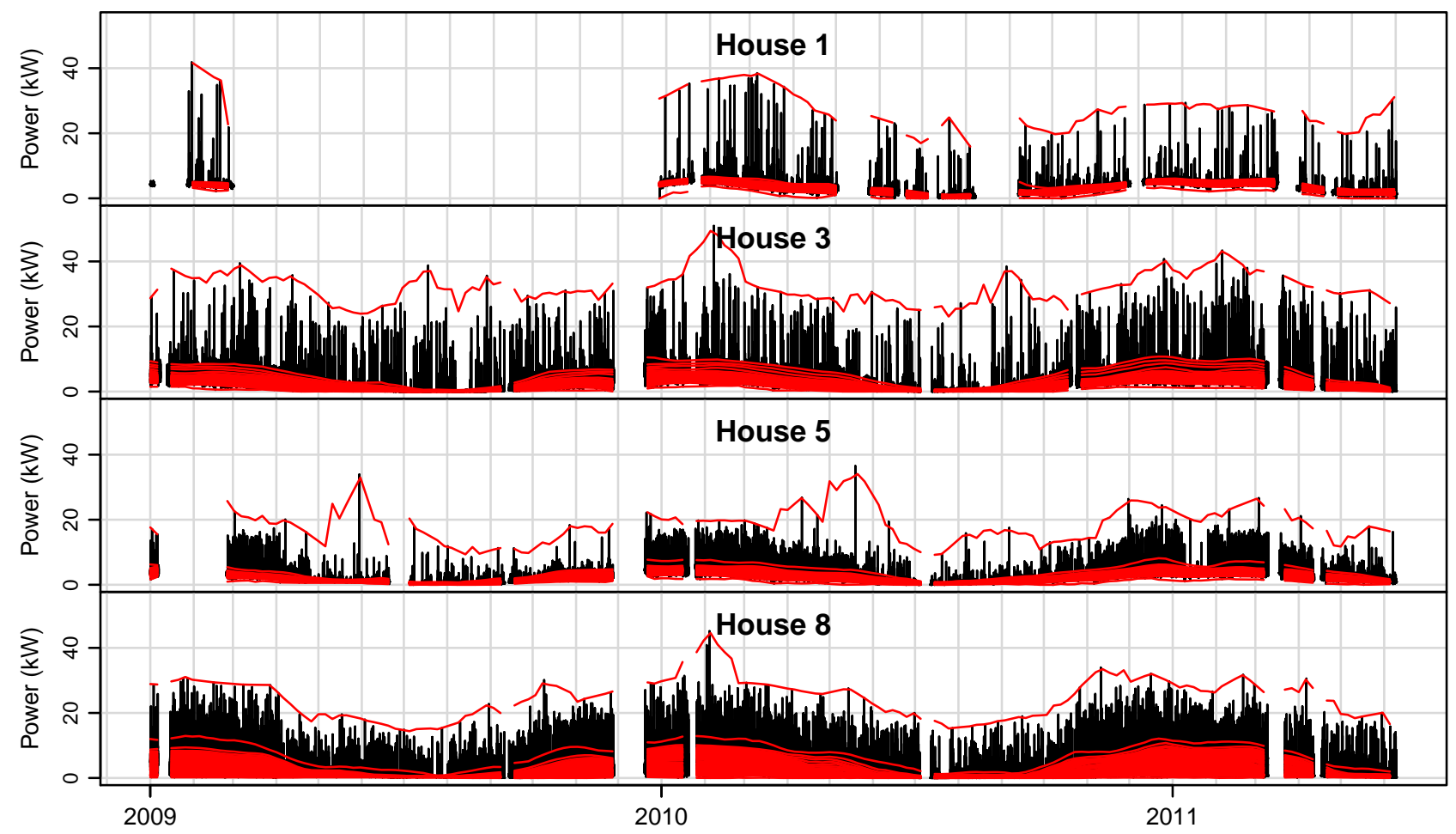

Figure 1: The heat load for four selected houses over the entire period, which is nearly spanning two and a half years. The red lines are estimates of the $0 \%, 2 \%, \ldots, 98 \%, 100 \%$ quantiles, which indicate the distribution of the heat load at a given time. 


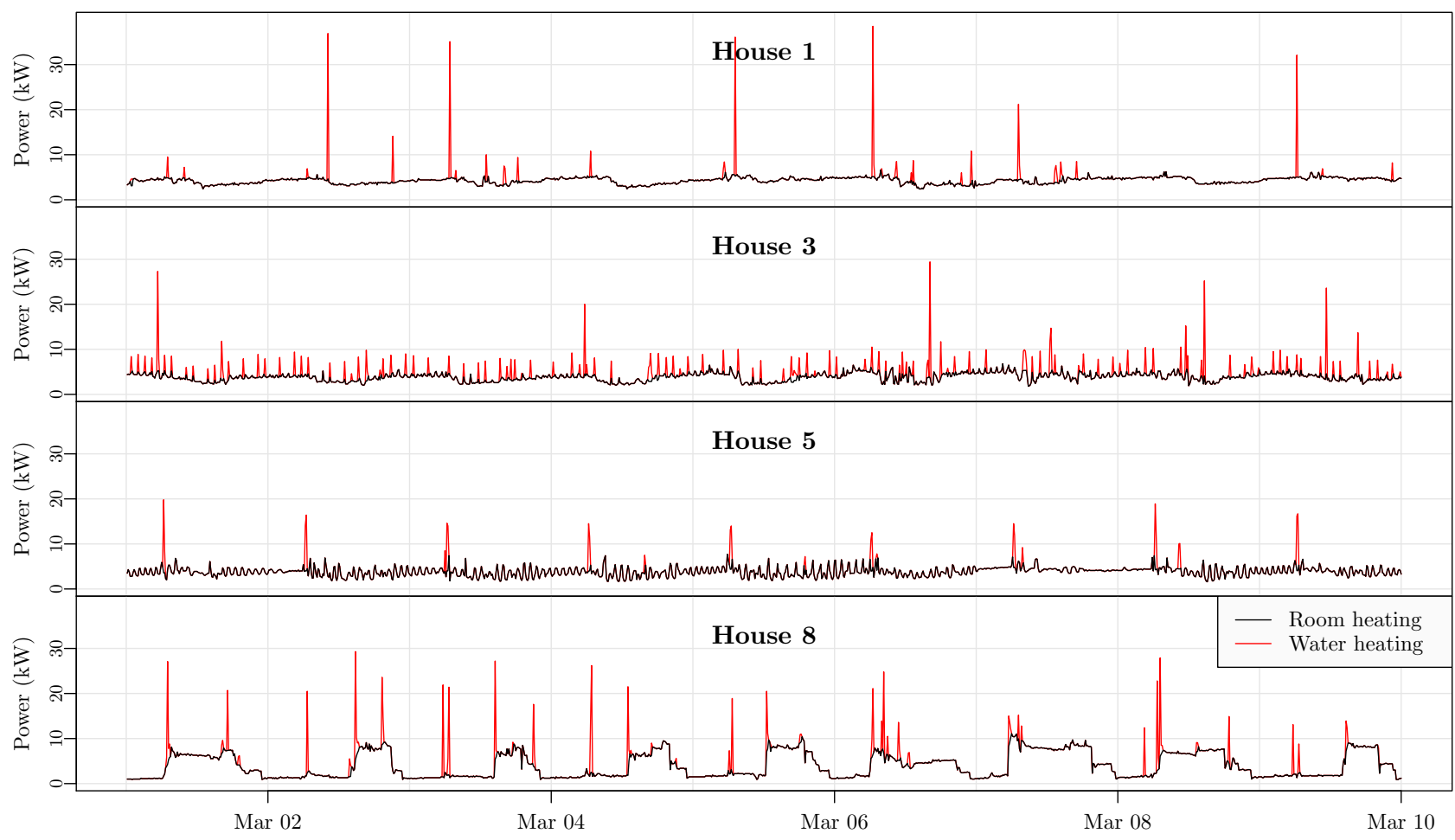

Figure 2: Heat load for four selected houses for the first 10 days of March in 2010. The peaks marked with red are the parts which are identified as hot water heating and the black line is the space heating part. Note that the hot water heating is added on top the space heating signal. 


\subsection{Numerical weather predictions}

The numerical weather predictions (NWPs) used for the forecasting are provided by the Danish Meteorological Institute. The NWP model used is DMI-HIRLAM-S05, which has a 5 kilometer grid and 40 vertical layers [15. The NWPs consist of time series of hourly values for climate variables, which are updated four times per day and have a 4 hour calculation delay (e.g. the forecast starting at 00:00 is available at 04:00). Since a new two-day heat load forecast is calculated every hour, then - in order to use the latest available information - every hour the latest available NWP value for the $k$ 'th horizon at time $t$ is picked as

$$
\begin{aligned}
& \text { Ambient temperature }\left({ }^{\circ} \mathrm{C}\right): T_{t+k \mid t}^{\mathrm{a}, \mathrm{nwp}} \\
& \text { Global radiation }\left(\mathrm{W} / \mathrm{m}^{2}\right): G_{t+k \mid t}^{\mathrm{nwp}} \\
& \text { Wind speed }(\mathrm{m} / \mathrm{s}): W_{t+k \mid t}^{\mathrm{s}, \mathrm{nwp}} \\
& \text { Wind direction }\left({ }^{\circ} \text { azimuth }\right): W_{t+k \mid t}^{\mathrm{d}, \mathrm{nwp}}
\end{aligned}
$$

\subsection{Combining local observations with NWPs}

To include the building heat dynamics in an efficient way, the inputs are low-pass filtered as explained in Section 3.3. Hence, for the forecast calculated at time $t$, past values of the inputs are being used. In order to use the information embedded in the local measurements they are combined with the NWPs. The combining is carried out by forming the time series for each of the inputs at time $t$, for a specific horizon $k$, by

$$
\begin{aligned}
\left\{T_{t+k \mid t}^{\mathrm{a}}\right\} & =\left\{\ldots, T_{t-1}^{\mathrm{a}, \mathrm{obs}}, T_{t}^{\mathrm{a}, \text { obs }}, T_{t+1 \mid t}^{\mathrm{a}, \mathrm{nwp}}, T_{t+2 \mid t}^{\mathrm{a}, \mathrm{nwp}}, \ldots, T_{t+k \mid t}^{\mathrm{a}, \mathrm{nwp}}\right\} \\
\left\{G_{t+k \mid t}\right\} & =\left\{\ldots, G_{t-1}^{\mathrm{obs}}, G_{t}^{\mathrm{obs}}, G_{t+1 \mid t}^{\mathrm{nwp}}, G_{t+2 \mid t}^{\mathrm{nwp}}, \ldots, G_{t+k \mid t}^{\mathrm{nwp}}\right\} \\
\left\{W_{t+k \mid t}^{\mathrm{s}}\right\} & =\left\{\ldots, W_{t-1}^{\mathrm{s} \text { obs }}, W_{t}^{\mathrm{s}, \mathrm{obs}}, W_{t+1 \mid t}^{\mathrm{s}, \mathrm{nwp}}, W_{t+2 \mid t}^{\mathrm{s}, \mathrm{nwp}}, \ldots, W_{t+k \mid t}^{\mathrm{s}, \mathrm{nwp}}\right\} \\
\left\{W_{t+k \mid t}^{\mathrm{d}}\right\} & =\left\{\ldots, W_{t-1 \mid t}^{\mathrm{d}, \mathrm{nwp}}, W_{t \mid t}^{\mathrm{d}, \mathrm{nwp}}, W_{t+1 \mid t}^{\mathrm{d}, \mathrm{nwp}}, W_{t+2 \mid t}^{\mathrm{d}, \mathrm{nwp}}, \ldots, W_{t+k \mid t}^{\mathrm{d}, \mathrm{nwp}}\right\}
\end{aligned}
$$

Notice that local observations are not available for the wind direction and that the most recent NWP is used for past values instead.

\section{Models}

As mentioned earlier the applied models are similar to the models used in [12] for forecasting of the summed total heat load for many houses. The models are based on prior physical knowledge of the heat dynamics of buildings, which in combination with statistical time series models, forms a grey-box modeling approach. This allows for inclusion of heat transfer effects related to the climate variables in combination with a time adaptive estimation scheme applied to meet changing condition. Furthermore, in order to describe of patterns in resident behavior, a diurnal curve is included. The forecasting models are fitted, by optimizing the parameters to minimize the root mean square error (RMSE) in an off-line setting. The fitting is carried out separately for each house and for each horizon $k$, which means that the same model formulation - i.e. same inputs and model structure - is used, only the parameter values for each house and horizon can vary. 


\subsection{Time adaptive models}

The models are fitted with the $k$-step recursive least squares scheme described in [16]. This means that the coefficients in the model can change over time and adapt optimally, in a least squares sense, to changing conditions. The coefficients are recursively updated, which means that only a few matrix operations are required to compute an updated forecast, hence the scheme is computationally very fast. It is a recursive implementation of a weighted least squares estimation, where the weights are exponentially decaying over time. A single parameter is required, the forgetting factor $\lambda$, which determines how fast input data is down-weighted. The weights are equal to

$$
w(\Delta t)=\lambda^{\Delta t}
$$

where $\Delta t$ is the age of the data in hours. This implies that for $\lambda=0.98$ the weights are halved in 34 hours, for $\lambda=0.995$ they are halved in 138 hours ( $\sim 6$ days) and for $\lambda=0.999$ in 693 hours $(\sim 29$ days $)$.

\subsection{Diurnal curve}

A diurnal curve is included in the models for describing systematic diurnal patterns in the heat load, which for example can be caused by a nightly setback and free heat from electrical appliances. The curve is modeled as a harmonic function using a Fourier series

$$
\mu\left(t_{\mathrm{tod}}, n_{\mathrm{har}}, \alpha_{\mathrm{diu}}\right)=\sum_{i=1}^{n_{\mathrm{har}}} \alpha_{i, 1}^{\mathrm{diu}} \sin \left(\frac{t_{\mathrm{tod}} i \pi}{12}\right)+\alpha_{i, 2}^{\mathrm{diu}} \cos \left(\frac{t_{\mathrm{tod}} i \pi}{12}\right)
$$

where $t_{\text {tod }}$ is the time of day in hours at time $t, n_{\text {har }}$ is the number of harmonics included in the Fourier series and $\alpha_{\text {diu }}$ is a vector consisting of the coefficients for the included harmonics. For all the applied models a curve is fitted for working days and another curve for weekends.

\subsection{Low-pass filtering for modeling of building heat dynamics}

The heat dynamics of a building can be described by lumped parameter RC-models, see for example [17, [18 and [19]. As described by [12] the response in the heat load to changes in the climate variables can be modeled with a rational transfer function, which is a description with an RC-model of the low-pass filtering effect through the building. In the applied models the simplest first order low-pass filter, with a stationary gain equal to one, is used. This is a model of the building heat dynamics formed by an RC-model with a single resistance and a single capacitor. As an example the transfer function from the ambient temperature to the heat load is

$$
Q_{t}=\alpha_{\mathrm{a}} H_{\mathrm{a}}(q) T_{t}^{\mathrm{a}}
$$

where

$$
H_{\mathrm{a}}(q)=\frac{1-a_{T_{\mathrm{a}}}}{1-a_{T_{\mathrm{a}}} q^{-1}}
$$

and where $q^{-1}$ is the backward shift operator $\left(q^{-1} x_{t}=x_{t-1}\right)$ (see [20]), $\alpha_{\mathrm{a}}$ is the stationary gain from the ambient temperature to heat load and $a_{T_{\mathrm{a}}} \in[0,1]$ is a parameter, which is corresponding to the time constant for the part of the building affected by changes in ambient temperature. A building with a high thermal mass and good insulation will have a relatively high $a_{T_{\mathrm{a}}}$, hence the filter parameter needs to be tuned for each building in order to describe the heat dynamics properly. First order low-pass filters are also applied for wind speed and global radiation, with the filter parameter tuned to match the response of the building to each effect separately. 


\subsection{Parameter optimization}

As described above several parameters need to be optimized for each house and horizon. The optimization is carried out in an off-line setting by minimizing the RMSE for each of the sixteen houses and for each horizon $k=1, \ldots, 42$ separately. This does require some computational power, for example for the low-pass filtering of the inputs. Therefore a simple bisectioning scheme is applied for the optimization, since this allows for performing a filtering of the inputs only once for parameter values in a given range. Then these series can be used for optimization for all the houses and horizons. The properties of the optimization is not studied in detail in this work, however some remarks regarding an operational implementation are given in the discussion in Section 7.

The following parameters are optimized:

- The forgetting factor: $\lambda$,

- The number of harmonics in the diurnal curve: $n_{\text {har }}$,

- The coefficients for input low-pass filters: $a_{T_{\mathrm{a}}}, a_{\mathrm{G}}$ and $a_{\mathrm{W}_{\mathrm{s}}}$.

\section{Model identification}

Forecasting models, which include different types of heat transfer effects related to the climate variables, are applied in order to identify which of the inputs are important to include. Furthermore, models in which the inputs enters differently are tried. See [12] for a description of how a physical model can be rewritten into the identifiable models, which are applied here. The model which include all energy contributions is

$$
Q_{t+k}=\widehat{Q}_{t+k \mid t}+e_{t+k}
$$

where

$$
\widehat{Q}_{t+k \mid t}=Q_{\mathrm{a}}+Q_{\mathrm{g}}+Q_{\mathrm{w}}
$$

where the $Q_{\text {name }}$ variables on the right side of the equation represent the heat contributions from the considered heat transfers as described in the following.

\subsection{First step in model selection}

To select a suitable forecasting model a forward selection approach is used. In the first step the model $_{\mathrm{D}}$

$$
\widehat{Q}_{t+k \mid t}=\alpha_{\mathrm{ia}}+\mu\left(t_{\mathrm{tod}}, n_{\mathrm{har}}, \alpha_{\mathrm{diu}}\right)
$$

which do not include any climate inputs, is fitted. In this model the heat load is simply modeled as a diurnal curve with an offset. Note that the offset $\alpha_{\mathrm{ia}}$ then represents a difference, which is constant over 24 hours, between the indoor and the ambient temperature, and that the diurnal curve will then capture diurnal patterns in both the indoor and ambient temperature in this model. Due to the time adaptive scheme this model will be able to track the slow changes in temperatures over the year. Finally, note also that the coefficients could have been denoted with a $t$ to indicate that they are changing over time, a house number to indicate that they are fitted to each house, 
and a $k$ to indicate that the model is fitted for each horizon separately, however these have been left out for better readability.

To find out if useful information can be gained from applying climate series as inputs to the model, the cross-correlation function (CCF), see [21], between the one-step ahead ( $k=1$ hour) prediction residuals for model $_{\mathrm{D}}$ and the available input series is calculated. Since there is a series of residuals for each house the average over all houses

$$
\bar{e}_{t+k}=\sum_{i=1}^{n_{\text {houses }}} e_{t+k}^{\text {House } i}
$$

where $n_{\text {houses }}=16$ are the number of houses and $e_{t+k}^{\text {House } i}$ is the residual series for House $i$, is used. In this way the CCF to each of the inputs can be summarized for all the houses in a single plot. This will of course only show if an input is generally important to include and not the effects for each individual house. The effects related to each house - which are different - are considered in later parts of the paper.

The CCF between the average residuals from $\operatorname{model}_{\mathrm{D}}$ to the inputs can be seen in Figure $3 \mathrm{a}$.

Clearly, very significant correlations between the residuals and both the ambient temperature, and the global radiation, but apparently none to the wind speed, are found. It is decided to add the ambient temperature as input to the model, which leads to $\operatorname{model}_{\mathrm{A}}$

$$
\widehat{Q}_{t+k \mid t}=Q_{\mathrm{a}}
$$

where

$$
Q_{\mathrm{a}}=\alpha_{\mathrm{ia}}+\mu\left(t_{\text {tod }}, n_{\text {har }}, \alpha_{\text {diu }}\right)+\alpha_{\mathrm{a}} H_{\mathrm{a}}(q) T_{t+k \mid t}^{\mathrm{a}}
$$

The $H_{\mathrm{a}}(q)$ is the low-pass filter describing the heat dynamics of the building envelope, i.e. the response of in heat load to changes in ambient temperature. Notice that the intercept $\alpha_{\mathrm{ia}}$ is representing a 24 hour constant indoor temperature modified by the diurnal curve.

In order to find out if any gain in forecasting performance is achieved from model $_{\mathrm{D}}$ to model $_{\mathrm{A}}$ the RMSE is used for evaluation as described in the following.

\subsubsection{Root mean square error evaluation}

To evaluate the models the root mean square error (RMSE) for the $k^{\prime}$ th horizon

$$
\operatorname{RMSE}_{k}=\left(\frac{1}{N} \sum_{t=1}^{N} e_{t+k}^{2}\right)^{\frac{1}{2}}
$$

is used together with the $\mathrm{RMSE}_{k}$ improvement

$$
I_{\mathrm{RMSE}}=100 \cdot \frac{\mathrm{RMSE}_{\mathrm{ref}}-\mathrm{RMSE}}{\mathrm{RMSE}_{\mathrm{ref}}}(\%)
$$

over the currently selected model as reference. It is noted values not in the heating season - which starts the 15'th of September and ends 15'th of May in Denmark - and values before the 15'th of March 2009, which is used as a burn-in period, are excluded from the $\mathrm{RMSE}_{k}$ calculation. For evaluation of the inclusion of ambient temperature, the $\mathrm{RMSE}_{k}$ improvement for model $_{\mathrm{A}}$ over model $_{\mathrm{D}}$ is calculated. The average improvement for all horizons (from $k=1$ to $k=42$ ) for each house is plotted in Figure 4a. A RMSE $k$ improvement for the each house in the range from 5 to 25 percent and around 14 percent in average is achieved. This is clearly a significant improvement, hence $\operatorname{model}_{\mathrm{A}}$ is preferred over $\operatorname{model}_{\mathrm{D}}$. 

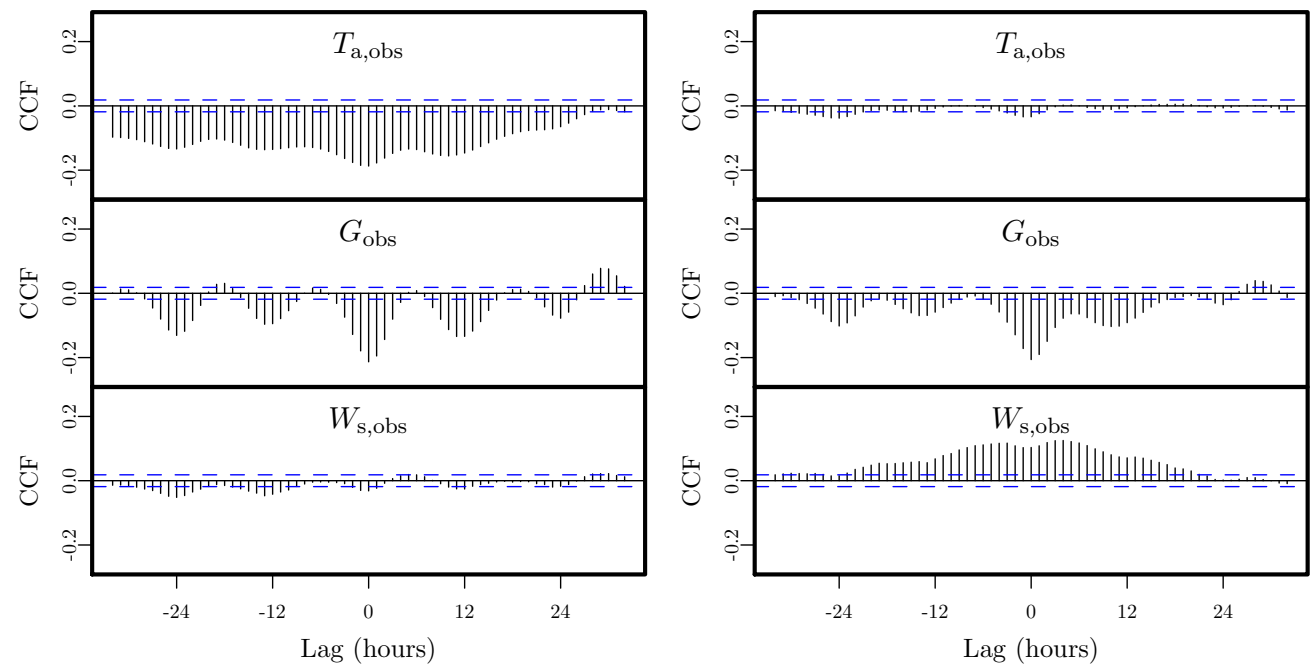

(a) Step one: CCF for model $_{\mathrm{D}}$ errors to the in-(b) Step two: CCF for $\operatorname{model}_{\mathrm{A}}$ errors to the puts inputs.
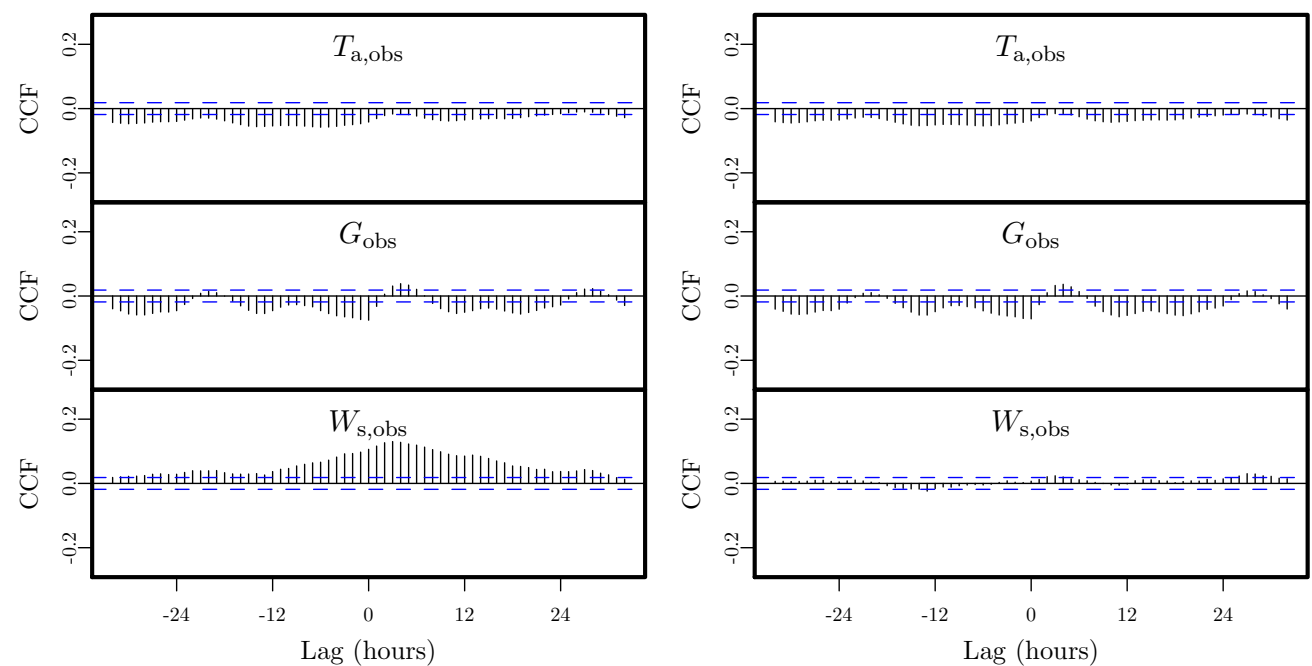

(c) Step three: CCF for model $_{\mathrm{A} . \mathrm{G}}$ errors to the(d) Step four: CCF for model $_{\mathrm{A} . \mathrm{G} . \mathrm{W}}$ errors to the inputs. inputs.

Figure 3: The cross-correlation function (CCF) between the average error series for the one-step ahead forecast (horizon $k=1$ ) and the local observations of the inputs, since the inputs for the one-step ahead forecasts are primarily formed by the observations. The plots are for the errors from the selected model in the four steps of model identification carried out. 


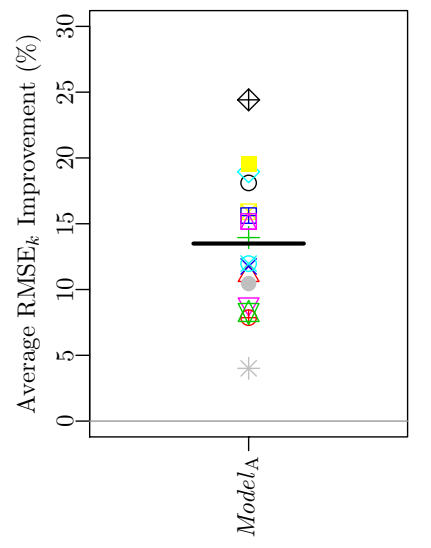

(a) Step one: Improvements over model $_{\mathrm{D}}$

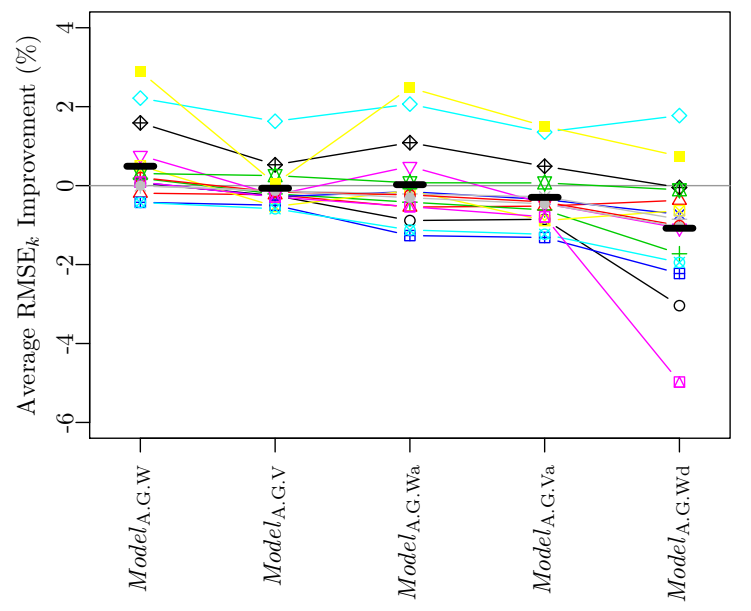

(c) Step three: Improvements over model $_{\mathrm{A} . \mathrm{G}}$

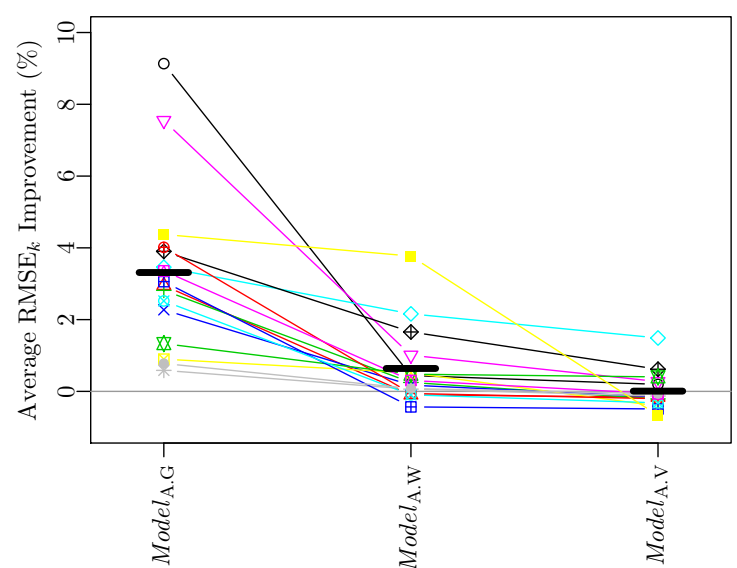

(b) Step two: Improvements over $\operatorname{model}_{\mathrm{A}}$

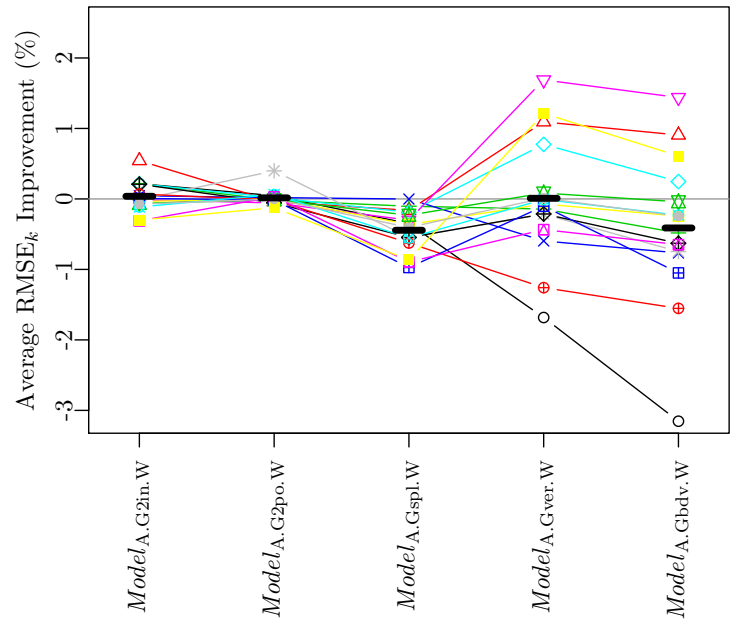

(d) Step four: Improvements over model $_{\text {A.G.W }}$

Figure 4: Improvements over the previously selected model for the models in each step of the selection. 


\subsection{Second step in model selection}

To explore the possibilities for further expansion of model $_{\mathrm{A}}$ the CCF from the average residuals (defined in Equation (12)) to each of the climate series is calculated and plotted in Figure 3b. The correlation to the ambient temperature is much lower than for $\operatorname{model}_{\mathrm{D}}$ and the correlation to the global radiation is more or less the same. The correlation to the wind speed has increased, most likely this correlation was "covered" by the correlation to the ambient temperature for model $\mathrm{D}$ residuals. Notice, that there is a significant correlation decaying over 12 to 24 hours to the lagged inputs indicating that dynamics should be included by low-pass filtering.

To find the most important extension of odel $_{\mathrm{A}}$ several extensions involving the global radiation or the wind speed are fitted (i.e. the $\mathrm{RMSE}_{k}$ is minimized by tuning the parameters listed in Section 3.4 for each house).

The first considered expansion is model $_{\mathrm{A} . \mathrm{G}}$

$$
\widehat{Q}_{t+k \mid t}=Q_{\mathrm{a}}+\alpha_{\mathrm{g}} H_{\mathrm{g}}(q) G_{t+k \mid t}
$$

where the heat gain from solar radiation is included by letting the global radiation enter through a low-pass filter, which describes the dynamic response from the global radiation to the heat load. The second expansion is model $_{\mathrm{A} . \mathrm{W}}$

$$
\widehat{Q}_{t+k \mid t}=Q_{\mathrm{a}}+\alpha_{\mathrm{ws}} H_{\mathrm{w}}(q) W_{t+k \mid t}^{\mathrm{s}}
$$

where the cooling of the building from wind is described by letting the wind speed enter through a low-pass filter. This is a model of wind cooling not depending on the ambient temperature, however - due to the time-adaptive modeling scheme - is does include the slow changes in temperature difference between indoor and ambient temperature. The third expansion is model $_{\mathrm{A} . \mathrm{V}}$

$$
\widehat{Q}_{t+k \mid t}=Q_{\mathrm{a}}+\alpha_{\mathrm{vent}} W_{t+k \mid t}^{\mathrm{s}}
$$

which includes the effect of ventilation by inputting the instant effect of wind speed to the heat load.

The $\mathrm{RMSE}_{k}$ improvements averaged over all horizons for each house for the considered expansions are plotted in Figure $4 \mathrm{~b}$, It is seen that the increase in performance is highest for all the houses using model $_{\mathrm{A} . \mathrm{G}}$, hence this model is preferred and used for expansion in the following step. In the remaining of the paper the heat contribution from solar radiation is denoted by

$$
Q_{\mathrm{g}}=\alpha_{\mathrm{g}} H_{\mathrm{g}}(q) G_{t+k \mid t}
$$

\subsection{Step three: Inclusion of wind speed in the model}

In the third step of the model identification several ways of including the wind speed is considered. First the CCF between the one-step ahead residuals, from the model selected in the previous step, model $_{\text {A.G }}$ and the inputs, are studied to see if any useful information is remaining in the climate series.

Firstly, it is noted that the correlation to the global radiation has decreased compared to the CCF plot for $\operatorname{model}_{\mathrm{A}}$, but that some is still left, indicating that the dynamic effects are not entirely described by the model. Secondly, it is noted that there is a significant cross-correlation to the wind speed and therefore an expansion which includes the wind speed is sought. Five different ways of letting the wind speed enter the model are tried as described in the following. 
The first expansion is formed by adding the wind speed through a low-pass filter for modeling of cooling of the building in model $_{\text {A.G.W }}$

$$
\widehat{Q}_{t+k \mid t}=Q_{\mathrm{a}}+Q_{\mathrm{g}}+\alpha_{\mathrm{ws}} H_{\mathrm{w}}(q) W_{t+k \mid t}^{\mathrm{s}}
$$

and, for modeling ventilation, the instant effect of wind speed is added in model $_{\text {A.G.V }}$

$$
\widehat{Q}_{t+k \mid t}=Q_{\mathrm{a}}+Q_{\mathrm{g}}+\alpha_{\mathrm{ws}} W_{t+k \mid t}^{\mathrm{s}}
$$

In the two models above the wind speed enter the model without the interaction with ambient temperature, which means that the temperature difference between the indoor and ambient temperature is modeled as constant and that changes are only tracked due to the adaptivity of the model. In the following two expansions the interaction is also included, with a filter in model $_{\text {A.G.Wa }}$

$$
\widehat{Q}_{t+k \mid t}=Q_{\mathrm{a}}+Q_{\mathrm{g}}+\alpha_{\mathrm{ws}} H_{\mathrm{w}}(q) W_{t+k \mid t}^{\mathrm{s}}+\alpha_{\mathrm{wsa}} H_{\mathrm{w}}(q) W_{t+k \mid t}^{\mathrm{s}} T_{t+k \mid t}^{\mathrm{a}}
$$

and as an instant effect in model $_{\text {A.G.Va }}$

$$
\widehat{Q}_{t+k \mid t}=Q_{\mathrm{a}}+Q_{\mathrm{g}}+\alpha_{\mathrm{ws}} W_{t+k \mid t}^{\mathrm{s}}+\alpha_{\mathrm{wsa}} W_{t+k \mid t}^{\mathrm{s}} T_{t+k \mid t}^{\mathrm{a}}
$$

Finally, the wind speed input coefficient is conditioned on the wind direction in odel $_{\text {A.G.Wd }}$

$$
\widehat{Q}_{t+k \mid t}=Q_{\mathrm{a}}+Q_{\mathrm{g}}+\sum_{i=1}^{4} \alpha_{\mathrm{i}} H_{\mathrm{w}}(q) K(u) W_{t+k \mid t}^{\mathrm{s}} T_{t+k \mid t}^{\mathrm{a}}
$$

where the kernel function

$$
K(u)=(1-|u|) \mathbf{1}_{\{|u| \leq 1\}}
$$

with

$$
u=\left(\left(W_{t+k \mid t}^{\mathrm{d}, \mathrm{nwp}}+45+(i-1) \cdot 90\right) \bmod 4\right)-1
$$

is used to create four input series, which are linearly interpolated as a function of the wind direction. The center of the kernels is thus at the most prevailing wind directions in Denmark, especially southwest in the winter period 22.

The plot in Figure $4 \mathrm{c}$ shows the improvements over model $_{\mathrm{A} . \mathrm{G}}$ for the five models. The improvement is quite different for each house, for some it is negative, which is because the forecasting model becomes over-parameterized. It is also seen that the pattern of the improvement among the houses are quite similar for the five models, indicating that for some houses the wind have a more prevalent effect than for others. Since model $_{\text {A.G.W }}$ generally have the most positive improvement and since it is the simplest extension, it is preferred over the others. In the remaining of the paper the model part describing the effect of wind is denoted with

$$
Q_{\mathrm{w}}=\alpha_{\mathrm{ws}} H_{\mathrm{w}}(q) W_{t+k \mid t}^{\mathrm{s}}
$$




\subsection{Step four: Enhancement of the solar model part}

In the final step the model part for solar radiation is enhanced in different ways, as described in the following. Studying the CCFs for model $_{\text {A.G.W }}$ in Figure 3d it is seen that the correlation between the residuals and the inputs has been decreased compared to the CCFs for the smaller models, however there is some left to the ambient temperature and solar radiation. From studying plots of the forecasts it is found that it might be possible to improve the model part in which the effect of solar radiation is included.

Firstly, an additional input for the solar gain is added and model $_{\mathrm{A} . G 2 \mathrm{in} . \mathrm{W}}$

$$
\widehat{Q}_{t+k \mid t}=Q_{\mathrm{a}}+Q_{\mathrm{g}}+\alpha_{\mathrm{g} 2} H_{\mathrm{g} 2}(q) G_{t+k \mid t}+Q_{\mathrm{w}}
$$

is formed. This allows for an additional dynamic response of the building to solar radiation. Notice that an additional filter coefficient for the $H_{\mathrm{g} 2}(q)$ filter is fitted.

Secondly, the solar radiation part is enhanced by using a two-pole filter instead of a one-pole filter

$$
\widehat{Q}_{t+k \mid t}=Q_{\mathrm{a}}+\alpha_{\mathrm{g}} H_{2 \mathrm{pol}}(q) G_{t+k \mid t}+Q_{\mathrm{w}}
$$

where

$$
H_{2 \text { pol }}(q)=\frac{1-a_{1}-a_{2}}{1-a_{1} q^{-1}-a_{2} q^{-2}}
$$

and

$$
a_{1}=a_{g_{1}}+a_{g_{2}} \text { and } a_{2}=-a_{g_{2}}
$$

The two filter coefficients thereby relate to different dynamics: $a_{g_{1}}$ is related to the highest time constant and $a_{g_{2}}$ is related to a faster time constant of the building.

In the third extension the solar radiation is separated into three inputs: one for the morning, one for the noon and one for the evening. This allows for the building to have different solar gains during the day. The model $_{\text {A.Gspl.w }}$ is

$$
\begin{aligned}
\widehat{Q}_{t+k \mid t}= & Q_{\mathrm{a}}+\alpha_{\mathrm{g} 1} H_{\mathrm{g}}(q) G_{t+k \mid t}^{\text {morning }}+\alpha_{\mathrm{g} 2} H_{\mathrm{g}}(q) G_{t+k \mid t}^{\text {noon }} \\
& +\alpha_{\mathrm{g} 3} H_{\mathrm{g}}(q) G_{t+k \mid t}^{\text {evening }}+Q_{\mathrm{w}}
\end{aligned}
$$

The three inputs are

$$
\begin{aligned}
G_{t+k \mid t}^{\text {morning }} & =G_{t+k \mid t} \mathbf{1}_{\left\{t+k \in\left[t_{\text {rise }}, t_{\text {rise }}+\Delta t\right]\right\}} \\
G_{t+k \mid t}^{\text {noon }} & =G_{t+k \mid t} \mathbf{1}_{\left\{t+k \in\left[t_{\text {rise }}+\Delta t, t_{\text {set }}-\Delta t\right]\right\}} \\
G_{t+k \mid t}^{\text {evening }} & =G_{t+k \mid t} \mathbf{1}_{\left\{t+k \in\left[t_{\text {set }}-\Delta t, t_{\text {set }}\right]\right\}}
\end{aligned}
$$

where $\mathbf{1}_{\{\cdot\}}$ is the indicator function, $t_{\text {rise }}$ and $t_{\text {set }}$ is the time of sunrise and sunset, respectively and $\Delta t=\left(t_{\text {set }}-t_{\text {rise }}\right) / 3$ is a third of the day length.

Finally, two enhancement are formed by projecting the solar radiation onto a vertical surface tracking the solar azimuth angle. The projection to vertical is carried out by first splitting the global radiation into a direct and a diffuse component as in [23] and onto a vertical surface with 
the Hay and Davies model [24, see also [25]. The effect of the projections is first of all an increase in the level of solar radiation when the sun elevation is low, i.e. in the morning and in the evening (or afternoon). In model $_{\mathrm{A} . G v e r . W}$

$$
\widehat{Q}_{t+k \mid t}=Q_{\mathrm{a}}+\alpha_{\mathrm{g}} H_{\mathrm{g}}(q) G_{t+k \mid t}^{\mathrm{ver}, \mathrm{tr}}+Q_{\mathrm{w}}
$$

the total vertical radiation is inputted and in model $_{\mathrm{A} . \mathrm{Gbdv} . \mathrm{W}}$

$$
\widehat{Q}_{t+k \mid t}=Q_{\mathrm{a}}+\alpha_{\mathrm{g} 1} H_{\mathrm{g}}(q) G_{t+k \mid t}^{\text {beam,tr }}+\alpha_{\mathrm{g} 2} H_{\mathrm{g}}(q) G_{t+k \mid t}^{\text {diffuse,tr }}+Q_{\mathrm{w}}
$$

the direct (or beam) and the diffuse component is inputted separately.

The models are fitted to each house and the RMSE improvements over model $_{\text {A.G.W }}$ are calculated and plotted in Figure 4d, For model $_{\text {A.G2in.W }}$ and model $_{\text {A.G2po.W only a little difference in per- }}$ formance is seen, and for model $l_{\mathrm{A} \text {.Gspl.W }}$ the performance has decreased. These three models become over-parameterized, however it is noted that for short horizons the improvement for model $_{\mathrm{A} \text {.Gin2.W }}$ is positive for all the houses. For the last two models: $\operatorname{model}_{\mathrm{A} . G v e r . \mathrm{W}}$ and $\operatorname{model}_{\mathrm{A} . \mathrm{Gbdv} . \mathrm{W}}$, the change in performance depends on the house. One interesting pattern is that the houses with the highest change (both decreased and increased) are the houses, which benefited most from addition of the solar radiation in the step second step of the model selection, as seen in the plot in Figure 4b. This indicates that increased performance can be obtained by modifying the solar gain over the day by learning an optimal diurnal solar gain curve for each house, however this is beyond the scope of the present study. In general no significant overall increase in performance is found for any of the five suggested enhancements, hence the model selection is ended. The presented results in the remaining of the paper are from model $_{\text {A.G.W }}$, together with a model of the noise, which is described in the following section.

\section{Noise model}

Considering the auto-correlation function $(\mathrm{ACF})$ for the one-step prediction residuals for the houses, shown in the upper plot of Figure 5, it is found that a model is useful for describing dynamical information embedded in the residuals. A simple auto-regressive (AR) model is fitted to the residuals with the recursive least squares scheme [16]. The AR(1) model

$$
e_{t+k}=a_{\mathrm{e}} e_{t}+e_{t+k}^{\text {noise }}
$$

is fitted for the residuals from the selected model model $_{\text {A.G.W }}$ for each horizon $k$. The ACF of the noise residuals $e_{t+k}^{\text {noise }}$ can be seen in the lower plot of Figure 5 . Compared to the upper plot the autocorrelation for lag 1 is significantly lower indicating that the noise model improves performance. Clearly, some of the houses still have significant auto-correlation left and for the short horizons a noise model, which include more lags would improve performance further. However it was tried to include one more lag (lag 2), but this did only improve the overall performance marginally, mainly because no performance improvement is achieved on longer horizons. The houses which have the highest ACF (in particular House 11 and 16) have some high frequency oscillations embedded in the heat load signal, as described in the following section where the results are discussed. The average $\mathrm{RMSE}_{k}$ improvement over all horizons is in the range of $0.35 \%$ to $6.7 \%$, hence a quite significant improvement, especially for some of the houses. The $\mathrm{RMSE}_{k}$ improvement for the one-step ahead forecasts is in the range $1.3 \%$ to $19 \%$, which clearly shows that the noise model is most important for short horizons. 


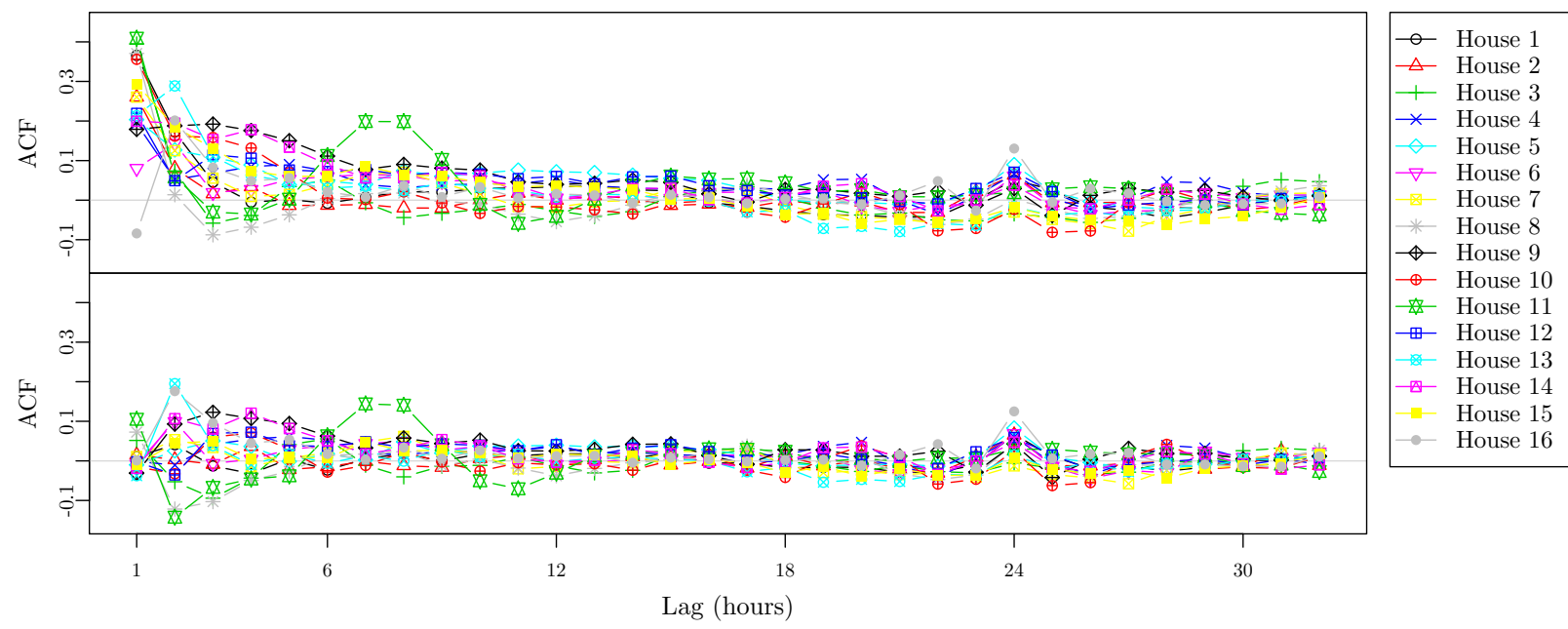

Figure 5: The auto-correlation function (ACF) for each house. The upper plot is the ACF of the errors before the AR(1) noise model is applied and the lower plot shows the ACF of the errors after.

\section{Results}

In this section the results from forecasting with the selected model are presented and discussed. First the parameters, which are fitted for each house, are reported and then the performance for individual houses is discussed.

\subsection{Model parameters}

The parameters, which are fitted for each house, are listed in Section 3.4. Since there is a value for each horizon for each house and for each parameter, they are reported with the plots in Figure 6. The general patterns are discussed in the following. Starting with the upper most plot in the figure, which is of the forgetting factor $\lambda$ in the recursive least squares scheme, it can be seen that it has a tendency to be lower for the first couple of horizons: for $k=1$ the average over all the house is 0.9755 , which implies that the weighting of the input data is halved in only 28 hours. This quick forgetting is most likely optimal, because it is profitable for the forecasting model to be able to react fast to changes in the system, e.g. residents increase the indoor temperature or open the windows, which can be tracked on short horizons. On longer horizons the forgetting is on a stable level: for $k=5$ the average is 0.9953 increasing to 0.9963 for $k=42$, which implies that the weighting of the input data is halved in around 8 days.

The second plot from the top in Figure 6 is of the optimized number of harmonics in the diurnal curve: a higher number means that it is profitable to include higher frequencies in the curve. Clearly, a huge variation among the houses is found, which is very reasonable, since the diurnal patterns are very different, this is shown below.

The middle plot of the figure is of the optimized coefficient for the low-pass filter transfer function from the ambient temperature to the heat load. Except for the two lower lines the variation for each house as a function of the horizon $k$ is quite small (in the range of \pm 0.01 ), which leads to the conclusion that the applied low-pass filtering describes the response of heat load to changes in ambient temperature for each house appropriately. In Table 1 the average coefficient 


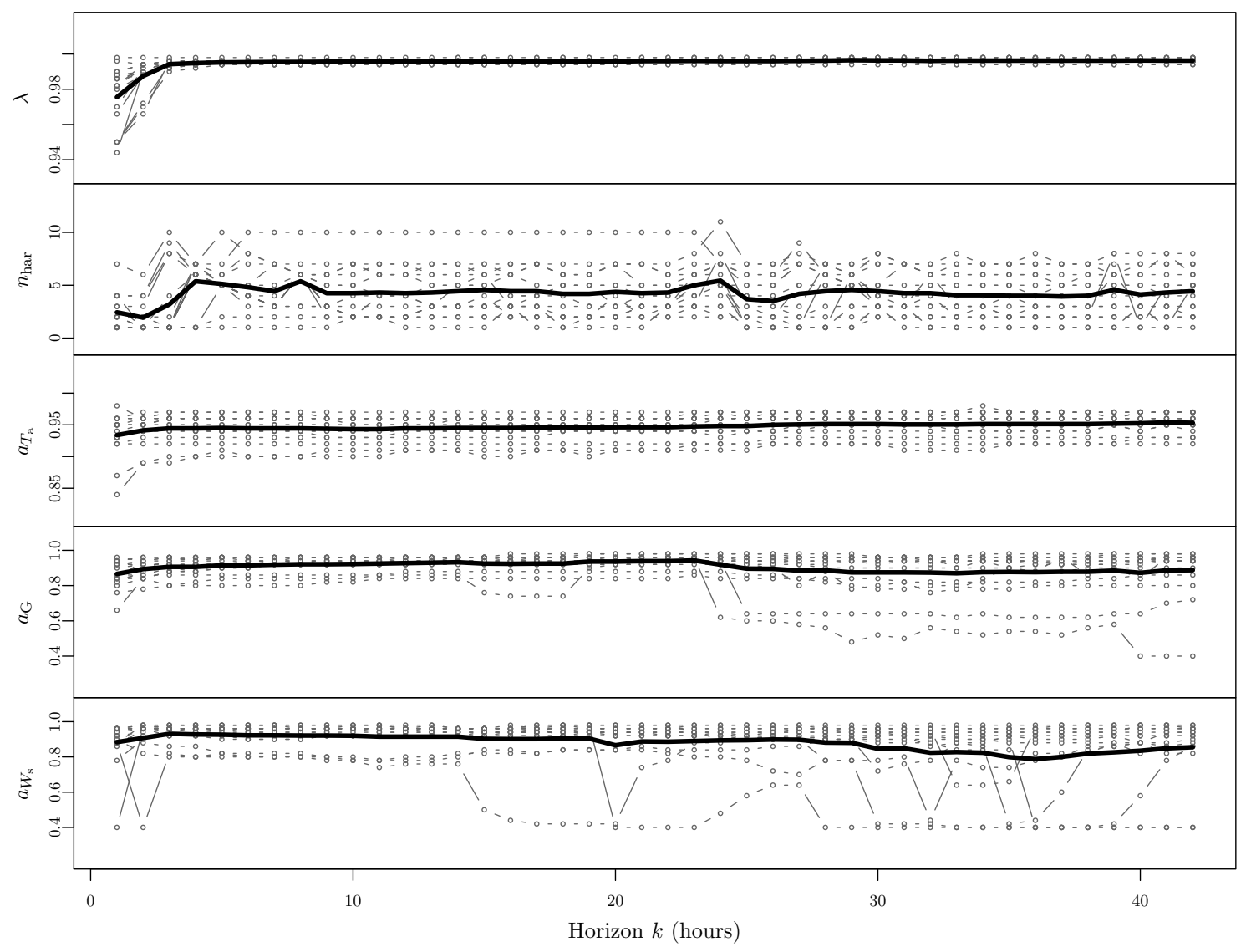

Figure 6: Values of the parameters fitted for each house.

for each house is listed together with the equivalent $\mathrm{RC}$ time constants. The values are within a reasonable range compared to values found in other studies [12, [5.

The fitted values of low-pass filter coefficient for global radiation $a_{\mathrm{G}}$ and for wind speed $a_{W_{\mathrm{s}}}$ are shown in the lower two plots of Figure 6. The values are all in the same range, generally between 0.8 and up to near 1 , but with some lower values for a couple of the houses, which are houses where the solar radiation and wind speed are not very important inputs.

\subsection{Forecasting performance}

In this section the forecasting performance is analyzed and discussed, especially the differences in performance among the houses. For evaluation of the performance the normalized root mean square error for each horizon

$$
\mathrm{NRMSE}_{k}=\frac{\mathrm{RMSE}_{k}}{\bar{Q}_{t}}
$$

is used, where $\bar{Q}_{t}$ is the average heat load for the house, which is calculated with the same values as used for calculation of the $\mathrm{RMSE}_{k}$ (see the text below Equation (15)).

The plot in Figure 7 shows the $\mathrm{NRMSE}_{k}$ as a function of the horizon $k$ for each house using the selected model $_{\text {A.G.W }}$ and the noise model. Clearly, the poorest forecasting performance is for 


\begin{tabular}{lcccccccc} 
House & 1 & 2 & 3 & 4 & 5 & 6 & 7 & 8 \\
\hline$a_{T_{\mathrm{a}}}$ & 0.96 & 0.91 & 0.91 & 0.96 & 0.94 & 0.96 & 0.95 & 0.96 \\
$\tau_{T_{\mathrm{a}}}$ (hours) & 27 & 11 & 10 & 25 & 16 & 27 & 21 & 26 \\
House & 9 & 10 & 11 & 12 & 13 & 14 & 15 & 16 \\
\hline$a_{T_{\mathrm{a}}}$ & 0.94 & 0.97 & 0.95 & 0.96 & 0.95 & 0.94 & 0.96 & 0.92 \\
$\tau_{T_{\mathrm{a}}}$ (hours) & 17 & 32 & 18 & 24 & 19 & 15 & 25 & 13
\end{tabular}

Table 1: Values of optimized low-pass filter coefficient for the response from ambient temperature to heat load and corresponding RC time constant $\tau_{T_{\mathrm{a}}}$ in hours.

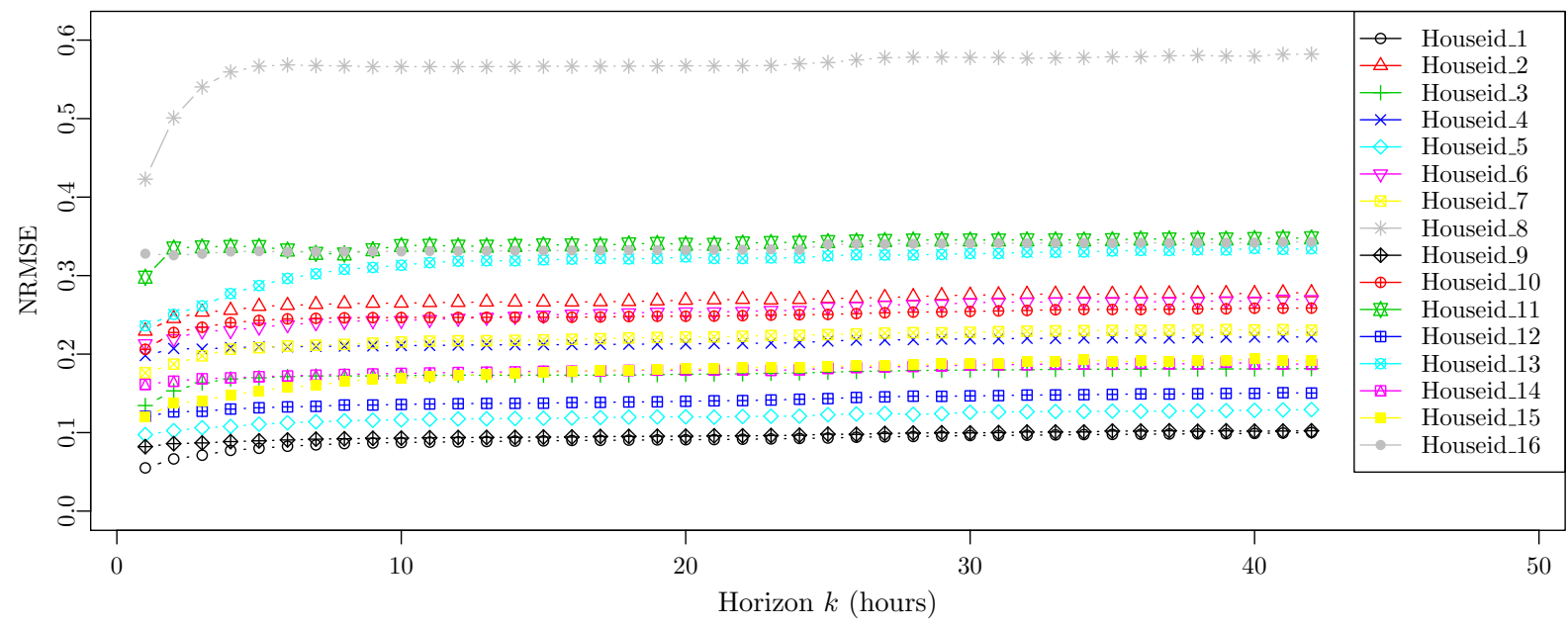

Figure 7: The $\mathrm{NRMSE}_{k}$ as a function of the horizon $k$ for model $_{\mathrm{A} . \mathrm{G} . \mathrm{W}}$ for each house.

House 8. The explanation is found by considering the plot for House 8 in Figure 8, which shows the heat load together with the 1 hour and 24 hour forecasts. The main reason for the poor forecasts is a very irregular diurnal curve. A nightly setback results in a high difference between day and night and the time of day at which the heat is switched to a high level again is not following a regular pattern. It is probably controlled manually by the residents. This is opposed to the nightly setback for House 10, which have a much more regular pattern which can be much better forecasted.

Another source for high errors is seen in the plots for House 2 and 16, where noisy fluctuations occur on the higher frequencies in the signals. The smaller fluctuations are probably partly from hot water heating, which was not well separated from the space heating, but clearly higher peaks which are not related to hot water heating are seen. For House 11 a more steady, but still quite unpredictable, pattern is seen, which is likely to come from some oscillation in the thermostatic control of the heat system.

The heat load signals for House 1,9 and 15 are much less volatile. These houses are also the ones with a lower $\mathrm{NRMSE}_{k}$, as seen from the plot in Figure 7. The most obvious point to notice is the deviation between the 1 and the 24 hour forecasts. Starting with the drop on the 21'st of February, which is followed well by the 1 hour forecast, but not by the 24 hour forecast. This drop is clearly caused by solar radiation. It is a clear-sky day, as seen by the high level of observed global radiation (the second uppermost plot of Figure 8), which is also predicted well by the 24 hour NWP. However the drop is not followed by the 24 hour load forecast, since the previous day was also forecasted as a clear-sky day by the 24 hour NWP, but it was not a clear-sky day as seen 
by the low observed level. Hence, there is a much higher uncertainty on the global radiation input to the 24 hour forecast model compared to the 1 hour forecast, which use mostly observations as input, and therefore the global radiation input is not given much weight in the 24 hour forecasting model. From the 1'st of March a sunny period begins and it can be seen how the 24 hour forecasts starts to track the mid-day drops in heat load, as more weight is put on the global radiation input due to the time adaptivity of the modeling scheme. Finally, it is noted that the drop the 23 'th of February and the peak the 27'th of February in the heat load for House 15 are not seen in the other heat loads. It is attributed to residents behavior, which cannot be predicted. However, it is tracked with a delay in the 1 hour forecast. 


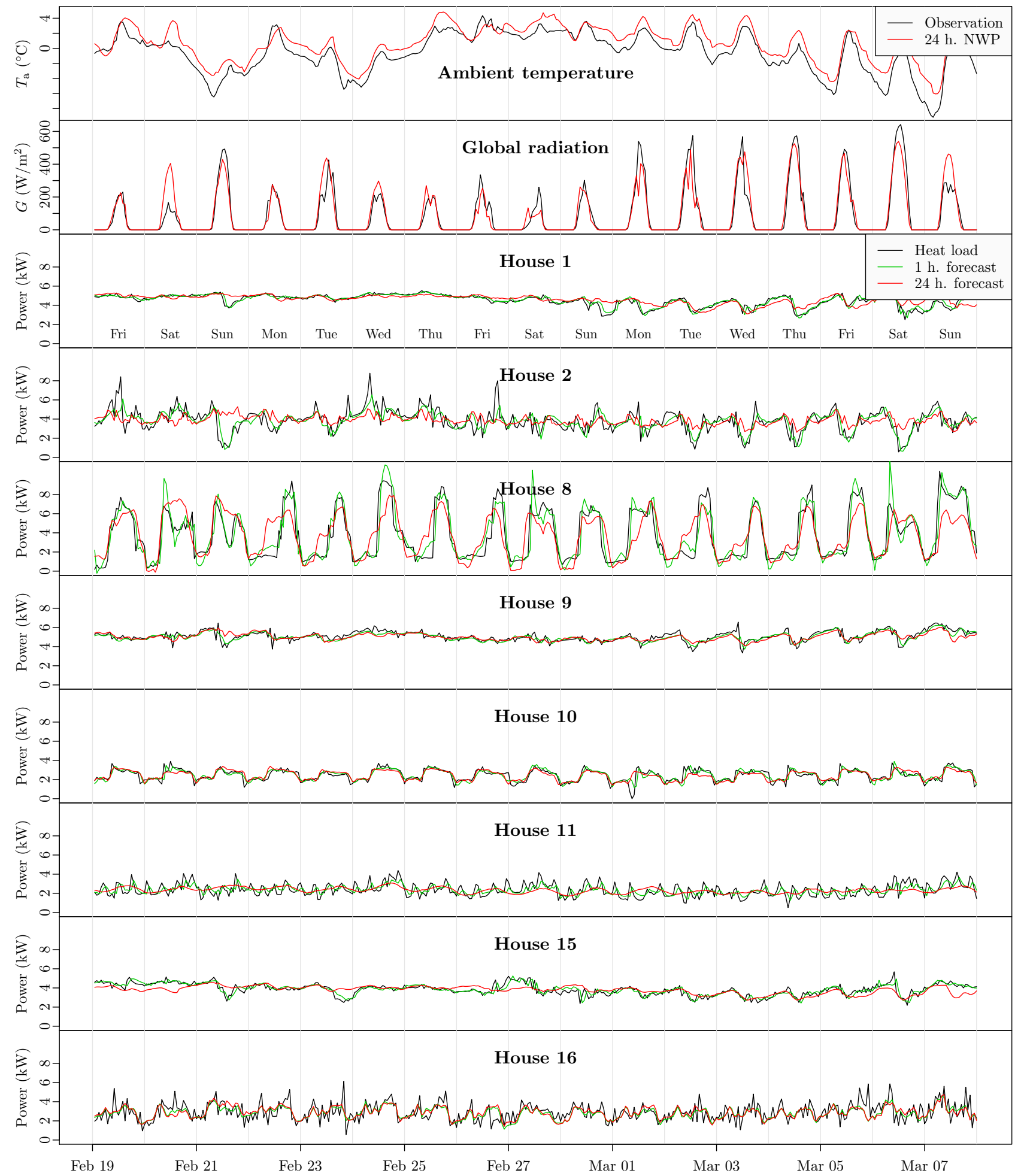

Figure 8: Plots of inputs and forecasts for sixteen days starting at the 19'th February 2010. The upper two plots are observations and the 24 hour NWP forecasts of the two most significant inputs: the ambient temperature and the global radiation. The plots below are for eight the houses of: observed heat load, 1 hour forecasts, and 24 hour forecasts. 


\section{Discussion}

The presented heat load forecasts can be used to form the input for optimization of the heat supply to buildings in smart grid applications. Such optimization can be based on model predictive control. It is especially useful for optimization of heating systems with a thermal storage medium, for example a hot water tank. For the data used in the study the indoor temperature was not available and it is therefore modeled as constant offset modified by a diurnal curve. If the indoor temperature is available it will allow for advancements of the method by including it as an input to the model. Thereby the estimation of a time constant for the building can be carried out with higher accuracy, which will allow the method to be used for optimization, where the thermal mass of the building is used for thermal storage. It is also noted that the type of linear time-adaptive models applied for the forecasting furthermore can be used for characterization and monitoring of the thermal performance of buildings [26]. Especially, the inclusion of user behavior is an important issue and should be further elaborated in studies focusing on such applications.

The forecasting method is found feasible to implement operationally and can be automatized to a high degree. Certainly, flawed data can cause problems, however schemes for identifying issues which needs manual handling can be implemented. Alarms could for example be triggered by unusual changes in coefficient estimates or unusually highly auto-correlated residuals. It is noted that the current implementation in $\mathrm{R} \mathrm{D}^{1}$ is not compiled code and can be further optimized. However, a test shows that around 1000 forecast updates (including the recursive parameter estimation) of the 42 hours forecasts using the selected model $_{\text {A.G.W }}$ can be calculated in approximately 10 seconds on a $2.4 \mathrm{GHz}$ single $\mathrm{CPU}$ computer. This is due to the computationally light recursive least squares scheme. If an update is needed every hour the time in-between updating can be used for data handling and off-line parameter optimization of the parameters listed in Section 3.4. The off-line optimization can be implemented with a recursive scheme and do not require updating very often, perhaps once a week. Based on this very coarse assessment it is found that operational implementation for a very large number of houses can be carried out with feasible amounts of computational power.

Regarding the model part in which the solar radiation is entering, is should be possible to achieve improvements in forecasting performance. For example more information about the individual buildings, such as the azimuth angle of the walls, would provide the possibility for projection of the radiation from horizontal to the vertical wall surfaces. However, it will be favorable for operation if no specific information about the buildings is needed. The non-linear functions, which could be applied with piecewise linear or regime switching functions depending on the level of solar radiation, or a non-parametric approach, could also taken with an off-line method for learning how the building respond to solar radiation over the day. Furthermore, it might be that performance can be increased by using different models depending on the horizon, especially it is more relevant to increase the model complexity for shorter horizons.

Finally, further work could be focused on modeling the uncertainties of the heat load forecasts. As found in the analysis of the results the two most important effects related to the uncertainties seems to be user behavior and solar radiation. Modeling the uncertainties is no trivial task since the uncertainties of the inputs propagates through the model and the relations change over time. One approach would be to characterize the uncertainties of the forecasted inputs and use this to build a model of the heat load forecast uncertainties. For example the uncertainties related to the

1 www.r-project.org 
user behavior will most likely have diurnal and regime shifting patterns which could be modeled with hidden Markov models.

\section{Conclusion}

A method for forecasting the load for space heating in a single-family house is presented. It is formed by adaptive linear time-series modeling techniques, using local observations and weather forecasts as input. Based on measurements from sixteen houses, a model, which is suitable for all the houses, is identified by using a forward selection approach. It is shown how the forecasting performance increases when the ambient temperature, global radiation and wind speed are added as inputs to the model. For inclusion of the heat dynamics of the building in the model a simple low-pass filter transfer function is used. In the last step of the model selection several enhancements of the model are tested, resulting in over-parameterization and decreased forecasting performance. In a second stage a noise model formed by an auto-regressive model is applied for modeling of the remaining dynamic information in the residuals. After applying the noise model, it is shown that almost no auto-correlation remains. The model parameters, which have been fitted individually for each house, are analyzed and it is found that they provide reliable information about the dynamic response of the buildings. The forecasting results are then analyzed thoroughly to give insight into the error sources, for example unpredictable behavior of the residents and uncertainty in the inputs, especially from the solar radiation weather forecasts. Finally, a discussion is given with ideas for applications and further advancements of the method.

\section{Acknowledgement}

Acknowledgements are given to the The Danish Council for Strategic Research, which have provided the financial support for the project "Solar/electric heating systems in the future energy system" (2104-07-0021) under which the work was carried out. The heat load and climate data was very kindly provided by Sønderborg Fjernvarme and the Danish Meteorological Institute is thanked for making their numerical weather predictions available.

[1] Danish Commission on Climate Change Policy, Grøn energi - vejen mod et dansk energisystem uden fossile brændsler, Tech. rep., Danish Energy Agency, dokumentationsdelen til Klimakommissionens samlede rapport (September 2010).

[2] Danish Commission on Climate Change Policy, Green energy - the road to a danish energy system without fossil fuels (September 2010).

[3] T. Pedersen, P. Andersen, K. Nielsen, H. Starmose, P. Pedersen, Using heat pump energy storages in the power grid, in: Control Applications (CCA), 2011 IEEE International Conference on, 2011, pp. 1106 -1111. doi:10.1109/CCA.2011.6044504

[4] T. Chen, Real-time predictive supervisory operation of building thermal systems with thermal mass, ENERGY AND BUILDINGS 33 (2) (2001) 141-150.

[5] T. Reddy, L. Norford, W. Kempton, Shaving residential air-conditioner electricity peaks by intelligent use of the building thermal mass, Energy 16 (7) (1991) 1001 - 1010. doi:10.1016/0360-5442(91)90060-Y

[6] G. P. Henze, C. Felsmann, G. Knabe, Evaluation of optimal control for active and passive building thermal storage, International Journal of Thermal Sciences 43 (2) (2004) 173 - 183. doi:10.1016/j.ijthermalsci. 2003.06 .001

[7] B. Perers, S. Furbo, J. Fan, E. Andersen, Z. Chen, Solar combisystems with forecast control to increase the solar fraction and lower the auxiliary energy cost, in: ISES Solar World Congress 2011 Proceedings, 2011, p. , presented at: ISES Solar World Congress, SWC ; 30 : Kassel, Germany, 2011.

[8] T. Mestekemper, Energy demand forecasting and dynamic water temperature management, Ph.D. thesis, Bielefeld University (2011). 
[9] E. Dotzauer, Simple model for prediction of loads in district-heating systems, Applied Energy 73 (3-4) (2002) 277 - 284. doi:10.1016/S0306-2619(02)00078-8.

[10] Q. Zhou, S. Wang, X. Xu, F. Xiao, A grey-box model of next-day building thermal load prediction for energyefficient control, International Journal of Energy Research 32 (15) (2008) 1418-1431. doi:10.1002/er.1458

[11] H. Nielsen, H. Madsen, D. E. F. P. og Fordeling af El og Varme, Predicting the heat consumption in district heating systems using meteorological forecasts, Tech. rep., DTU IMM (2000).

[12] H. A. Nielsen, H. Madsen, Modelling the heat consumption in district heating systems using a grey-box approach, Energy \& Buildings 38 (1) (2006) 63-71. doi:10.1016/j.enbuild.2005.05.002.

[13] R. Koenker, Quantile Regression, Cambridge University Press, 2005.

[14] P. d. Saint-Aubain, Adaptive load forecasting, Master's thesis, Technical University of Denmark (2011).

[15] D. M. I. DMI, DMI-HIRLAM-S05 (2011). URL http://www.dmi.dk/eng/index/research_and_development/dmi-hirlam-2009.htm

[16] P. Bacher, H. Madsen, H. A. Nielsen, Online short-term solar power forecasting, Solar Energy 83 (10) (2009) $1772-1783$.

[17] H. Madsen, J. Holst, Estimation of continuous-time models for the heat dynamics of a building, Energy and Buildings 22 (1) (1995) 67-79.

[18] J. E. Braun, N. Chaturvedi, An inverse gray-box model for transient building load prediction, HVAC\&R Research 8 (1) (2002) 73-99. arXiv:http://www.tandfonline.com/doi/pdf/10.1080/10789669.2002.10391290, doi: 10.1080/10789669.2002.10391290.

[19] M. Jiménez, H. Madsen, K. Andersen, Identification of the main thermal characteristics of building components using matlab, Building and Environment 43 (2) (2008) 170-180. doi:10.1016/j.buildenv.2006.10.030

[20] H. Madsen, Time Series Analysis, Chapman \& Hall, 2007.

[21] G. Box, G. Jenkins, G. Reinsel, Time series analysis, Holden-day San Francisco, 1976.

[22] J. Cappelen, B. Jørgensen, Observed wind speed and direction in denmark - with climatoligical standards normals, 1961-90, Tech. rep., Danish Meteorological Institute (1999).

[23] J. Ruiz-Arias, H. Alsamamra, J. Tovar-Pescador, D. Pozo-Vázquez, Proposal of a regressive model for the hourly diffuse solar radiation under all sky conditions, Energy Conversion and Management 51 (5) (2010) 881893. doi:10.1016/j.enconman.2009.11.024

[24] J. Hay, J. Davies, Calculation of the solar radiation incident on an inclined surface, in: Proc. 1st Canadian Solar Radiation Data Workshop, Vol. 59, 1980, p. .

[25] D. Reindl, W. Beckman, J. Duffie, Evaluation of hourly tilted surface radiation models, Solar Energy 45 (1) (1990) 9 - 17. doi:10.1016/0038-092X (90)90061-G

[26] H. A. Nielsen, Estimation of UA-values for single-family houses, Tech. rep., ENFOR (2008). 